\title{
Development of a Fire Detection System Using FT-IR Spectroscopy and Artificial Neural Networks
}

\author{
Yonggang Chen, Michael A. Serio, and Sandeep Sathyamoorthy \\ Advanced Fuel Research, Inc., 87 Church Street, East Hartford, CT 06108, USA
}

\begin{abstract}
Extensive measurements of flaming and smoldering fires and nuisance/environmental sources were performed with Fourier Transform Infrared (FT-IR) spectroscopy of gas phase products. A neural network model was formulated using the so-called Learning Vector Quantization (LVQ) network approach. The LVQ approach contains input and output layers with a hidden layer being a Kohenen layer. The hidden layer learns and performs classification. The inputs to the network are concentrations (from FT-IR measurements) of eighteen (18) gas species. The outputs of the network are classification of the input data as a flaming fire, smoldering fire, nuisance or environmental source. The network was trained and tested using the test data collected during this project. The results were very successful as, among the 248 cases tested, only 12 cases were misclassified, mostly due to the difficulties in classifying the modes of combustion during a transition from a smoldering to a flaming fire. Each case represents the gas phase concentration data at a time step from one of the validation fires, which were different types of fires from the training set. A first generation fire detection system using FT-IR gas measurements and neural networks has been built and implemented.
\end{abstract}

KEYWORDS: Fire Detection, Infrared Diagnostics, Neural Networks, False Alarms, FT-IR Gas Measurements

\section{INTRODUCTION}

Future fire detection systems should have the ability to discriminate signatures between fire and non-fire sources, because nuisance alarm problems have plagued existing smoke detectors. Current residential smoke detectors can respond very quickly, but suffer from the inability to discriminate between real fire smoke and other sources. Data from 1980's U.S. fire incidents show that $95 \%$ of smoke alarm signals were for non-hazardous conditions [1]. Even with the redundancy used in current aircraft fire detection systems, with the aim that a fire detector responds positively to a real fire and negatively to a non-threatening condition, false alarms versus real fires are at a ratio between 10:1 and 500:1[2,3]. The consequences of a detector mistakenly classifying a nuisance signal as a fire threat are costly and sometimes 
dangerous. In high value installations, such as semiconductor clean rooms and telephone central offices, it is obvious that reliable fire detection systems are needed, since usually these detection systems are used to activate fixed fire suppression systems, and false discharges are certainly undesirable. False alarms can cause unnecessary down time and undermine the operator's confidence in the monitoring systems.

In view of this problem, researchers have attempted to use multi-sensor measurements together with advanced artificial intelligence methods to build a new generation of fire detection systems over the last decade [4-9]. Okayama et al [6-8] were one of the first research groups to apply an artificial intelligence method, neural networks, for fire detection, although with limited success. Okayama used odor sensors together with a backpropagation neural network [10] to successfully distinguish between smoldering fires and environmental sources such as coffee powder and perfume [6]. They experimented with several neural network models using inputs from a CO sensor, a temperature sensor, and a smoke sensor to obtain fire probability, fire risk, and smoldering fire probability [8]. Milke and his colleagues have substantially furthered the work of Okayama $[4,11,12]$. More sensors $\left(\mathrm{CO}, \mathrm{CO}_{2}\right.$, Taguchi, and smoke and temperature) were used in Milke's studies. They also tested more extensive fire (flammable liquid, paper, cotton, polystyrene, cardboard, etc,) and non-fire (environmental) (furniture polish, toast, nail polish remover) sources [4,11,12]. Both large $[4,11]$ and small $[12]$ scale tests were performed.

Principal component analysis (PCA) was conducted for large scale test data [11] and results showed that PCA of sensor data can improve the discriminations of flaming, smoldering fires and nuisance sources, but a high probability of false alarms still exists. An elementary expert system was developed for the same large scale test data [12] which uses appropriate $\mathrm{CO}_{2}$ or temperature levels, levels of Taguchi sensor readings, and $\mathrm{CO}$ levels to distinguish flaming, smoldering fire and nuisance sources. The expert system correctly classified the flaming source, while $62 \%$ of smoldering and $87 \%$ of nuisance and ambient sources were also correctly identified. It is not surprising to learn that the greatest challenge lies in distinguishing between smoldering and nuisance/environmental sources. A so-called ellipsoidal neural network was used to process the small scale data for a variety of fire and non-fire sources [4], and success rates were much higher when compared to the expert systems described above (scale differences should not make such a high difference). They also acknowledged that the network failed to accurately classify the smoldering fire (only $60 \%$ success), as these are often misclassified as environmental sources. The explanation of this problem could be the lack of experimental data, but more likely it is due to the limitation of sensors which produce similar responses between smoldering sources and environmental excursions. Another drawback from that work [4], which the author did not clarify, is that the neural network was only used to do classification at maximum (peak) excursions (temperature, concentration), and hence the accuracy of the method at an earlier stage (for early detection of hazardous conditions) was not known.

Ishii et al. [13] used a time-delayed neural network to identify fire and non-fire situations for a limited number of tests they conducted. The use of historical information (previously collected data) in the neural network architecture can reduce false alarms, given the transient nature of fire and other excursion phenomena. Another interesting aspect of their approach 
was the use of the ASET smoke transport model in a reverse way, i.e., temperature, smoke concentration and $\mathrm{CO}$ concentration near the ceiling from the sensors were employed to calculate such quantities as heat release rate, smoke generation rate, and $\mathrm{CO}$ generation rate, which in turn were used as the inputs to the neural network. This approach is similar to the so-called hybrid first principles-neural network method [14]. In general, this hybrid method is more accurate than a neural network approach alone [14]. However, Ishii's work only involved a handful of tests, and the use of the simple smoke transport model ASET should be carefully reviewed. Nevertheless, their approach represents one of the most promising methods in developing new fire detection systems and is worthy of further investigation. Other attempts to improve fire detection have included gas sensing $[15,16]$ and smoke detectors with new algorithms [17].

We have previously demonstrated that an FT-IR based system is feasible to detect flaming fires [5,9] in studies where the FT-IR measurements of fire and non-fire gases were made in open-path, cross duct, and extractive modes. The current effort is concentrated on extractive mode measurements, since the most of the current fire detection technologies (e.g. VESDA and AnaLaser) for cleanrooms and telephone central offices are based on air sampling techniques where the air samples from multiple locations of the rooms are drawn and delivered through an extensive piping network to a particle analyzer. The FT-IR system can be easily incorporated in this type of fire detection system, and comparisons with existing technologies can be made. The rich gas phase information from an FT-IR spectrometer can be processed by an appropriate neural network model to build an intelligent fire detection system, as described below.

\section{EXPERIMENTAL}

Smoldering fires and environmental/nuisance sources were the focus of the current project, as flaming fires were extensively tested previously [5,9]. The experimental set-up is depicted in Fig. 1, where a smoldering fire test is illustrated. A hot plate was placed on a fire brick base. The sample was placed on the hot plate with a wire mesh screen in between. A sampling port was located about three feet above the sample. The gas sample was filtered and transported through heated tubes to an FT-IR gas cell. The heated tubes were maintained at about $150^{\circ} \mathrm{C}$ to prevent water condensation (condensation of water would cause inaccurate analysis of some gases, especially $\mathrm{HCl}$ ). For flaming fire tests, a methane torch was used to ignite the sample and the sample was mounted vertically. In most cases, the burning side of the sample was exposed to an external heat flux supplied by two radiant heaters (manufactured by Research Inc.). The nuisance or environmental sources were simulated by either introducing gases (e.g., $\mathrm{CF}_{4}$ ) through the same tube that delivered methane to the pilot, or placing a volatile liquid in a 6" diameter pan. A welding machine was used to supply high voltage and current to smolder a cable, simulating cable overheating by a power surge. These tests were conducted in AFR's $600 \mathrm{~m}^{3}$ Laboratory Combustion Facility (LCF), and an On-Line Technologies Multi-Gas FT-IR 2010 spectrometer was primarily used for the measurements, although a few flaming fire tests were measured using a Bomem MB100 FT-IR spectrometer. Numerous materials were tested, including Polyurethane (PU), Polyvinylchloride (PVC), Polymethylmethacrylate (PMMA), Polypropylene (PP), Polystyrene (PS), Douglas fir wood (DF), low density Polyethylene (LDPE), aqueous Ammonia $\left(\mathrm{NH}_{3}\right)$, Tetrafluoromethane $\left(\mathrm{CF}_{4}\right)$, 
Isopropyl alcohol (IPA), regular extension cable, and coaxial cable. The materials were burned in flaming and/or smoldering modes. Selected tests were repeated to check the reproducibility.

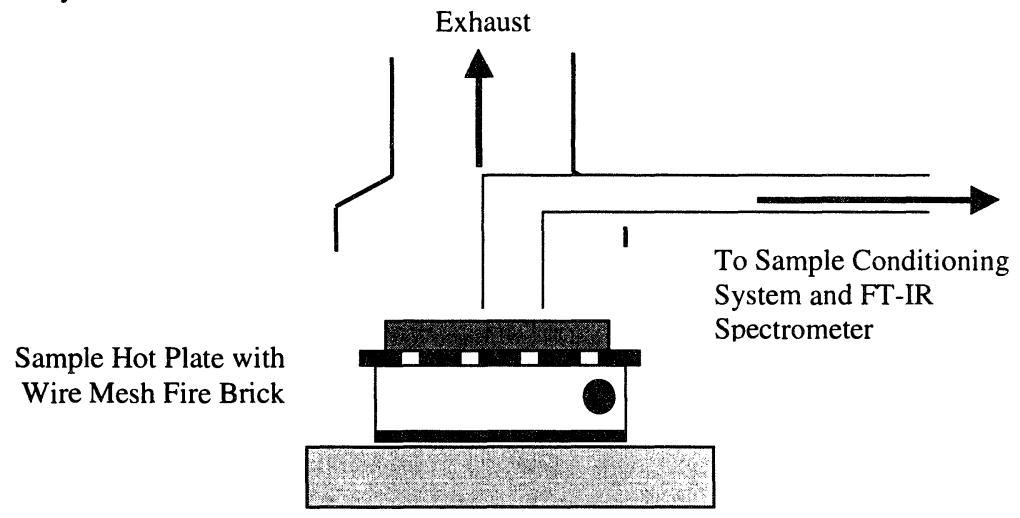

Figure 1. A schematic diagram of FT-IR gas measurements of fire and non-fire events.

\section{ANALYSIS OF EXPERIMENTAL DATA}

The gas-phase combustion (and before ignition) products from a fire can be classified into different categories: 1) volatile fuels; 2) pre-ignition pyrolysis products; 3) fuel-specific combustion products; 4) non-specific combustion products $\left(\mathrm{CO}, \mathrm{CO}_{2}, \mathrm{H}_{2} \mathrm{O}\right)$. By analyzing raw spectra from the FT-IR measurements, one can see clearly the fingerprints of some distinctive species evolved from the burning of materials, as illustrated in Figs. $2 a$ and $2 b$. Fig. 2a shows part of a spectrum (2700-3100 $\mathrm{cm}^{-1}$ ) from a smoldering fire of a regular extension cable (with a PVC jacket). The evolution of $\mathrm{HCl}$ is evident, although the $\mathrm{HCl}$ band is overlapped somewhat with a hydrocarbon band. It is also not surprising to see $\mathrm{HCl}$ evolution from a PVC smoldering fire (in fact it is a pyrolysis process) as shown in Fig. 2 b.

Fig. 3 shows concentrations of some fuel-specific species from burning different materials. $\mathrm{N}_{2} \mathrm{O}$ and formaldehyde were clearly observed in a Douglas fir smoldering-flaming fire test shown in Fig. 3a, while a fairly large amount of $\mathrm{C}_{2} \mathrm{H}_{4}$ and $\mathrm{C}_{2} \mathrm{H}_{2}$ can be noticed in a smoldering-flaming fire test of LDPE (Fig. 3b). Aside from observing the evolution of regular species such as $\mathrm{CH}_{4}$ and $\mathrm{CH}_{3} \mathrm{OH}$ from burning polymeric materials, large amounts of $\mathrm{HCl}$ (peak concentration of $\sim 160 \mathrm{ppm}$ ) from smoldering regular extension cables were also observed (Figs. 3c, 2a). Table 1 summarizes the gas species detected by the FT-IR during excursions (fire or non-fire) of various materials.

We have analyzed $\mathrm{CO} / \mathrm{CO}_{2}$ data from both the flaming and smoldering modes of various fires. Fig. 4 illustrates the $\mathrm{CO}$ and $\mathrm{CO}_{2}$ concentrations and the ratio of $\mathrm{CO} / \mathrm{CO}_{2}$ during an LDPE smoldering-flaming fire test. It can clearly be seen that this ratio drops from around 5 to less than 0.5 when the smoldering fire became a flaming fire. The $\mathrm{CO}$ and $\mathrm{CO}_{2}$ concen- 
PVC Cable Smoldering
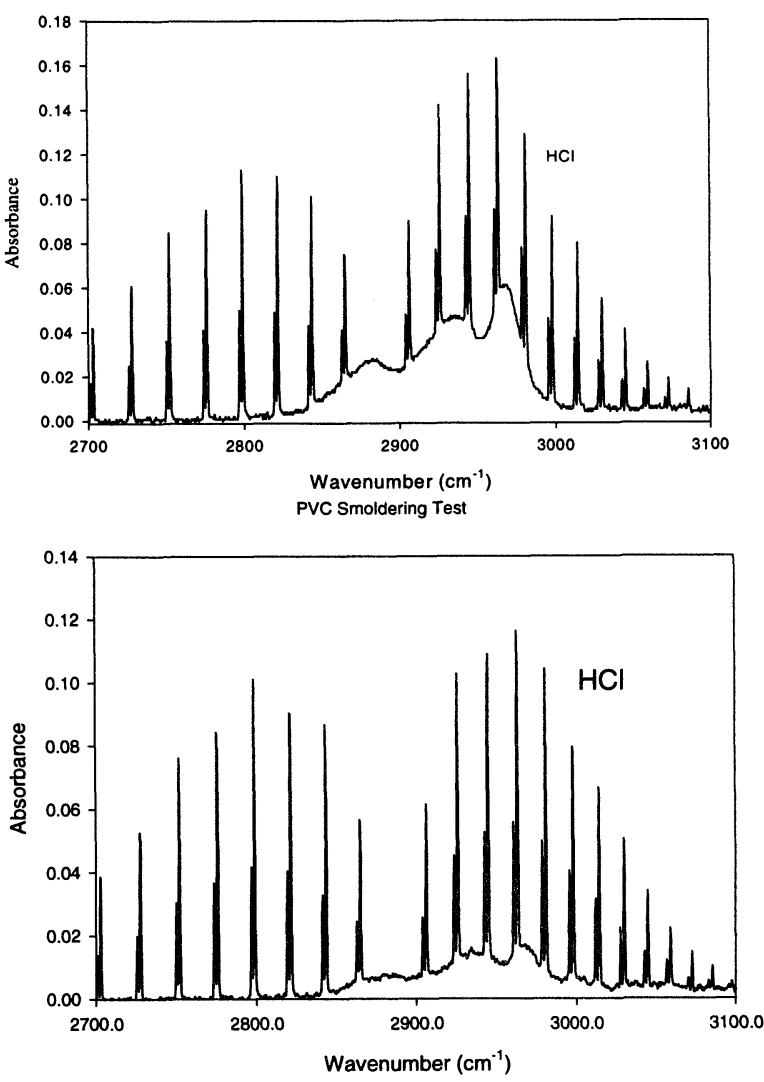

Figure 2. Absorbance spectra collected during smoldering fire tests of a cable (with PVC insulation) (2a) and PVC sheet (2b). $\mathrm{HCl}$ was observed as both spectra show distinctive $\mathrm{HCl} \mathrm{IR}$ bands over the region of $2700-3100 \mathrm{~cm}^{-1}$ trations can be employed to discriminate between flaming and smoldering fires using a simple rule-based expert system with reasonable success if the concentrations are high enough [4]. Fig. 5a shows the ratios of $\mathrm{CO}$ and $\mathrm{CO}_{2}$ from FT-IR measurements of flaming (circular symbols) and smoldering (triangular symbols) fire tests of Douglas fir. One can see that, except for the initial stage, the $\mathrm{CO} / \mathrm{CO}_{2}$ ratio is around 0.01 from the flaming Douglas fir fire, while this ratio is increasing during the smoldering stage and reaches around 1.3. The $\mathrm{CO} / \mathrm{CO}_{2}$ ratios at peak concentrations from flaming fires using Milke's data [4] are usually less than 0.02 (mostly much less) while these ratios for smoldering fires are generally larger than 0.03 .

In general, this ratio is a good indicator of whether there is a flaming or smoldering fire. However, the $\mathrm{CO} / \mathrm{CO}_{2}$ ratio does not seem to strictly follow this rule, as one can see from a LDPE flaming fire (Fig. 5b) where this ratio is around 0.3 . It follows that the $\mathrm{CO} / \mathrm{CO}_{2}$ ratio alone is not sufficient to indicate whether there is a flaming or smoldering fire for some cases. It would be more difficult to discriminate between smoldering, flaming fires and 

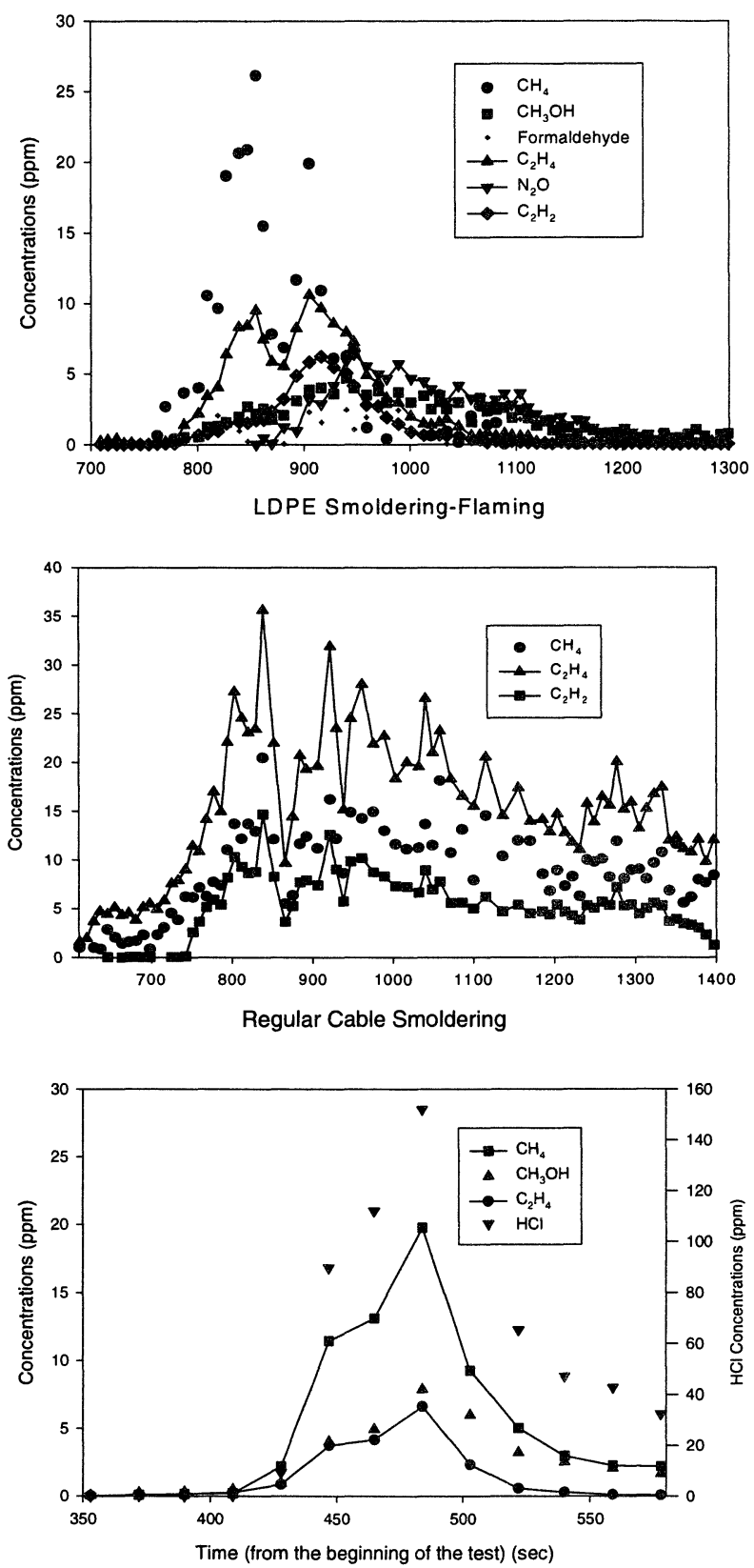

nuisance sources. More information is needed in order to make this classification. In fact, Milke [12] used $\mathrm{CO}$ and $\mathrm{CO}_{2}$ concentrations together with a Taguchi sensor (measuring oxidizable gases) signals in a simple expert system which failed to distinguish between smoldering fires and nuisance sources with reasonable accuracy. Measurements of other fire signatures (e.g., light scattering, temperature) are needed and, more importantly, advanced signal processing techniques are necessary in order to develop an intelligent fire detection system.

Figure 3a. Fuel-specific combustion products were detected by an FT-IR from a smoldering-flaming Douglas fir fire test as evidenced by the observation of $\mathrm{CH}_{4}$, $\mathrm{CH}_{3} \mathrm{OH}$, formaldehyde and $\mathrm{N}_{2} \mathrm{O}$.

Figure 3b. Same as Figure $3 \mathrm{a}$, except fuel-specific species, $\mathrm{CH}_{4}, \mathrm{C}_{2} \mathrm{H}_{4}$ and $\mathrm{C}_{2} \mathrm{H}_{2}$ were observed during an LDPE fire test.

Figure 3c. Fuel-specific species evolution history of regular extension cable smoldering fire test. The cable had a PVC jacket and a large amount of $\mathrm{HCl}$ (peak value $150 \mathrm{ppm}$ ) was observed. 
Table 1: Species Observed By FT-IR During Fire and Non-Fire Tests

\begin{tabular}{|c|c|c|c|c|c|}
\hline Material & $\begin{array}{l}\text { Excursion } \\
\text { Type }\end{array}$ & $\begin{array}{l}\text { Volatile } \\
\text { Fuels }\end{array}$ & $\begin{array}{l}\text { Pyrolysis } \\
\text { Products }\end{array}$ & $\begin{array}{l}\text { Fuel Specific Combustion } \\
\text { Products }\end{array}$ & $\begin{array}{l}\text { Non-Specific } \\
\text { Combustion } \\
\text { Products }\end{array}$ \\
\hline Douglas fir & $\begin{array}{l}\text { Flaming and } \\
\text { Smoldering }\end{array}$ & & & $\begin{array}{l}\mathrm{CH}_{4}, \mathrm{CH}_{3} \mathrm{OH}, \mathrm{C}_{2} \mathrm{H}_{2}, \mathrm{~N}_{2} \mathrm{O} \text {, } \\
\mathrm{C}_{2} \mathrm{H}_{4} \text {, formaldehyde, hydro- } \\
\text { carbons }\end{array}$ & $\mathrm{CO}_{2}, \mathrm{CO}, \mathrm{H}_{2} \mathrm{O}$ \\
\hline PVC & Smoldering & & $\mathrm{HCl}$ & $\begin{array}{l}\mathrm{CH}_{4}, \mathrm{CH}_{3} \mathrm{OH}, \mathrm{C}_{2} \mathrm{H}_{4}, \mathrm{HCl} \\
\text { hydrocarbons }\end{array}$ & $\mathrm{CO}_{2}, \mathrm{CO}, \mathrm{H}_{2} \mathrm{O}$ \\
\hline PVC & $\begin{array}{l}\text { Smoldering } \\
\text { and Flaming }\end{array}$ & & $\mathrm{HCl}$ & $\begin{array}{l}\mathrm{CH}_{4}, \mathrm{CH}_{3} \mathrm{OH}, \mathrm{C}_{2} \mathrm{H}_{2}, \mathrm{C}_{2} \mathrm{H}_{4}, \\
\mathrm{HCl} \text {, hydrocarbons }\end{array}$ & $\mathrm{CO}_{2}, \mathrm{CO}, \mathrm{H}_{2} \mathrm{O}$ \\
\hline PS & Flaming & & & $\begin{array}{l}\mathrm{CH}_{4}, \mathrm{C}_{2} \mathrm{H}_{2}, \mathrm{C}_{2} \mathrm{H}_{4}, \text { styrene, } \\
\text { hydrocarbons }\end{array}$ & $\mathrm{CO}_{2}, \mathrm{CO}, \mathrm{H}_{2} \mathrm{O}$ \\
\hline PS & Smoldering & & & $\begin{array}{l}\mathrm{CO}_{2}, \mathrm{CO}, \mathrm{H}_{2} \mathrm{O}, \mathrm{CH}_{3} \mathrm{OH}, \\
\mathrm{C}_{2} \mathrm{H}_{4}, \mathrm{C}_{3} \mathrm{H}_{6}, \text { styrene, hydro- } \\
\text { carbons }\end{array}$ & $\mathrm{CO}_{2}, \mathrm{CO}, \mathrm{H}_{2} \mathrm{O}$ \\
\hline $\begin{array}{l}\text { Polypropylene } \\
\text { (PP) }\end{array}$ & Flaming & & & $\mathrm{C}_{2} \mathrm{H}_{2}, \mathrm{C}_{2} \mathrm{H}_{4}$, hydrocarbons & $\mathrm{CO}_{2}, \mathrm{CO}, \mathrm{H}_{2} \mathrm{O}$ \\
\hline PMMA & Flaming & & MMA & $\begin{array}{l}\mathrm{C}_{2} \mathrm{H}_{4}, \mathrm{C}_{6} \mathrm{H}_{6}, \mathrm{MMA} \text {, hydro- } \\
\text { carbons }\end{array}$ & $\mathrm{CO}_{2}, \mathrm{CO}, \mathrm{H}_{2} \mathrm{O}$ \\
\hline PMMA & Smoldering & & MMA & $\mathrm{C}_{2} \mathrm{H}_{4}$, MMA, hydrocarbons & $\mathrm{CO}_{2}, \mathrm{CO}, \mathrm{H}_{2} \mathrm{O}$ \\
\hline PU & Smoldering & & & $\begin{array}{l}\mathrm{CH}_{4}, \mathrm{CH}_{3} \mathrm{OH}, \mathrm{NO} \text {, formal- } \\
\text { dehyde, hydrocarbons }\end{array}$ & $\mathrm{CO}_{2}, \mathrm{CO}, \mathrm{H}_{2} \mathrm{O}$ \\
\hline LDPE & $\begin{array}{l}\text { Smoldering } \\
\text { and Flaming }\end{array}$ & & & $\begin{array}{l}\mathrm{CH}_{4}, \mathrm{CH}_{3} \mathrm{OH}, \mathrm{C}_{2} \mathrm{H}_{2}, \mathrm{C}_{2} \mathrm{H}_{4}, \\
\text { hydrocarbons }\end{array}$ & $\mathrm{CO}_{2}, \mathrm{CO}, \mathrm{H}_{2} \mathrm{O}$ \\
\hline $\begin{array}{l}\text { Regular exten- } \\
\text { sion Cable }\end{array}$ & Smoldering & & & $\begin{array}{l}\mathrm{CH}_{4}, \mathrm{CH}_{3} \mathrm{OH}, \mathrm{C}_{2} \mathrm{H}_{2}, \mathrm{~N}_{2} \mathrm{O} \text {, } \\
\mathrm{C}_{2} \mathrm{H}_{4}, \mathrm{HCl}, \mathrm{NO} \text {, hydrocar- } \\
\text { bons }\end{array}$ & $\mathrm{CO}_{2}, \mathrm{CO}, \mathrm{H}_{2} \mathrm{O}$ \\
\hline Coaxial Cable & Smoldering & & & $\begin{array}{l}\mathrm{CH}_{4}, \mathrm{CH}_{3} \mathrm{OH}, \mathrm{C}_{2} \mathrm{H}_{2}, \mathrm{C}_{2} \mathrm{H}_{4}, \\
\mathrm{HCl}, \mathrm{NO} \text {, hydrocarbons }\end{array}$ & $\mathrm{CO}_{2}, \mathrm{CO}, \mathrm{H}_{2} \mathrm{O}$ \\
\hline Ammonia & $\begin{array}{l}\text { Vaporiza- } \\
\text { tion }\end{array}$ & $\mathrm{NH}_{3}$ & & N/A & \\
\hline IPR & $\begin{array}{l}\text { Vaporiza- } \\
\text { tion }\end{array}$ & IPR & & N/A & \\
\hline IPR & Flaming & IPR & & $\begin{array}{l}\text { IPR, } \mathrm{CH}_{4}, \mathrm{C}_{2} \mathrm{H}_{6}, \mathrm{C}_{2} \mathrm{H}_{4} \text {, hy- } \\
\text { drocarbons }\end{array}$ & $\mathrm{CO}_{2}, \mathrm{CO}, \mathrm{H}_{2} \mathrm{O}$ \\
\hline Freon $\mathrm{CF}_{4}$ & Release & $\mathrm{CF}_{4}$ & & N/A & \\
\hline
\end{tabular}

\section{BUILDING OF NEURAL NETWORK MODELS}

In the past decade, significant efforts have been made to develop computing strategies that simulate biological systems. The resulting artificial neural networks (ANN) are very simple in comparison to biological networks (such as human brains), but are well suited for performing tasks such as pattern recognition, cost minimization, etc. $[18,19]$. A typical ANN is 


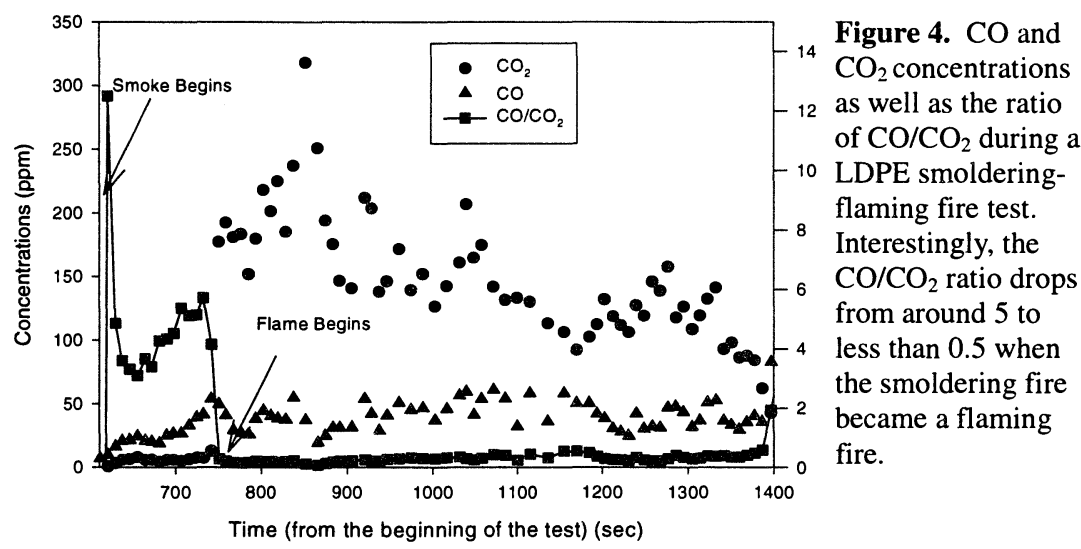

made up of three layers of processing units (nodes) and weighted connections between the layers of nodes. The input data is introduced at the input layer and is fed to the hidden layer through the weighted connections. Each node of the hidden layer sums its output of the network. The function of the network is determined by the activation functions applied by the nodes and by the weights of the connections between the nodes. The weights can be strong or weak, and positive (excitatory) or negative (inhibitory). Typically, nonlinear activation functions (sigmoidal, hyperbolic tangent) are used in order to allow the network to adapt to nonlinear problems.

Once the configuration of the ANN is defined for a given application, and the appropriate activation functions are selected, a network must be trained to perform the desired task. This is analogous to "learning" in a biological system. The usual method involves introducing training data to the ANN and comparing the output of the network to the correct or desired output. The error is then propagated back through the network and adjustments are made to the weights. This process is repeated until the error level falls below an acceptable level.

Neural network and fuzzy logic models can be used to identify whether there is a fire or nonfire (environmental nuisance) event, and to classify whether it is a flaming or smoldering fire, if the event is indeed a fire. Numerous neural network models have been used in developing a new generation of fire detection systems $[4,6,8,13]$. They have used the most popular backpropagation neural network techniques [10], and classifications of different modes of fires as well as non-fire source were made with good success. The inputs to the networks are all similar, including smoke sensors, odor sensors, temperature and heat release rate measurements, measurements of some non-fuel-specific species such as, $\mathrm{CO}, \mathrm{CO}_{2}$, and $\mathrm{O}_{2}$. 


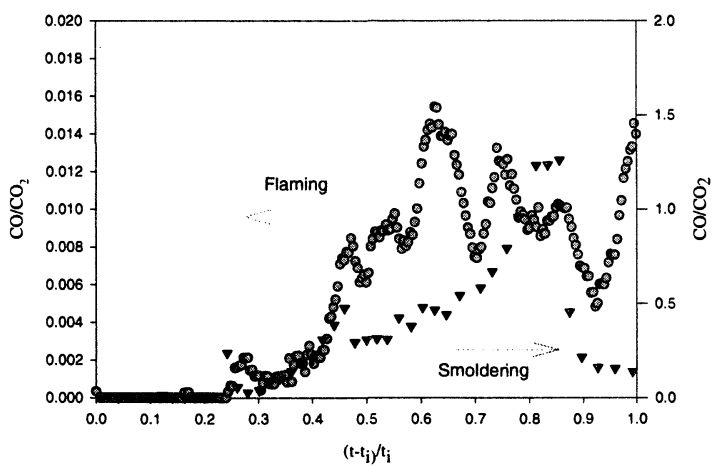

Figure 5a. $\mathrm{CO} / \mathrm{CO}_{2}$ ratios of flaming $(\bullet)$ and smoldering $(\nabla)$ fires of Douglas fir obtained by FTIR measurements. $t_{i}$ is the time the hot plate was turned on for the smoldering fire and is the time the sample was ignited during the flaming fire test.

LD Polyethylene Flaming Fire

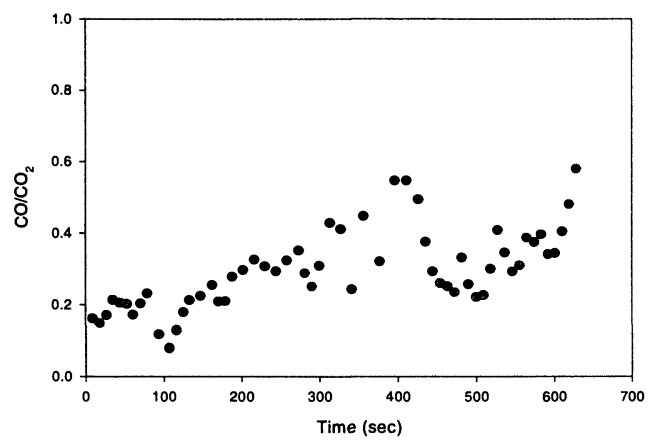

Figure $5 b . \mathrm{CO} / \mathrm{CO} 2$ ratio from a LDPE flaming fire test. The ratio is around 0.3 which is higher than that of the early stages of the smoldering fire of the Douglas fir (cf. Figure 5a).
Numerous neural network paradigms are available, and a discussion of this field is beyond the scope of the current paper. Nevertheless, we can conclude by intuition and experience that a backpropagation or a so-called Learning Vector Quantization (LVQ) network approach [20] could be utilized. As a first attempt, a LVQ network is carefully constructed. The LVQ approach contains, of course, input and output layers with a hidden layer being a Kohonen layer. This hidden layer learns and performs classifications as shown in Fig. 6.

A commercially available neural network software package, NeuralWorks Professional II/Plus [21], was chosen to build the needed neural network. The advantage of this approach is that an LVQ network can be built, easily modified, and different convergence criteria can be tested. The inputs to the network are concentrations (from FT-IR measurements) of $\mathrm{CO}_{2}, \mathrm{CO}$, $\mathrm{H}_{2} \mathrm{O}, \mathrm{CH}_{4}, \mathrm{CH}_{3} \mathrm{OH}$, Formaldehyde, $\mathrm{HCl}, \mathrm{C}_{2} \mathrm{H}_{4}, \mathrm{~N}_{2} \mathrm{O}, \mathrm{NH}_{3}$, $\mathrm{CF}_{4}$, NO, Methyl Methacrylate, Isopropyl alcohol, $\mathrm{C}_{2} \mathrm{H}_{6}, \mathrm{C}_{3} \mathrm{H}_{6}$, $\mathrm{C}_{6} \mathrm{H}_{14}, \mathrm{C}_{2} \mathrm{H}_{2}, \mathrm{C}_{6} \mathrm{H}_{6}$. The outputs of the network classify the input data as a flaming fire,

smoldering fire, nuisance or environmental source.

A total of 32 sets of experimental data were used to build the LVQ network. The network was first trained using data on PMMA, DF, PVC, coaxial Cable, PS, PP, $\mathrm{NH}_{3}, \mathrm{CF}_{4}$. The rest of the experimental data (IPA Spill, LDPE fires, PU fires, regular cable fires) were used to 
validate the trained LVQ network. The results were very successful as, among the 248 cases of time series data tested, only 12 cases

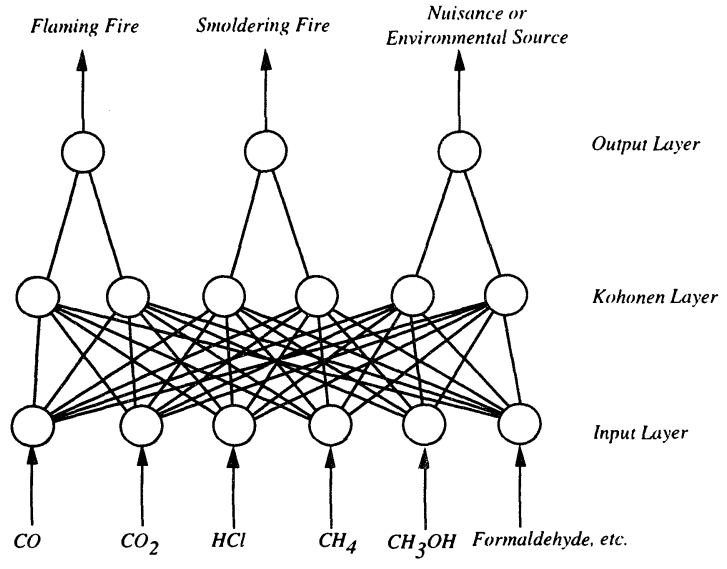

Figure 6. A Learning Vector Quantization (LVQ) neural network model for classification of fire and nonfire events. The inputs of the model are the gas species concentrations measured by an FT-IR spectrometer and the output of the model identifies fire and nonfire events as well as the modes of combustion. were misclassified, mostly due to the difficulties in classifying the modes of combustion during the transition from smoldering to flaming fires. Each case represents the gas concentration data at a time step from one of the validation fires or nuisance sources, which were different types of materials from that of the training set. The success rate was about $96 \%$, and could be improved by further training and optimization of the network. We should emphasize that the raw concentration data were used with no additional processing, and the network was used to do the classification at every time step. We believe that with more careful data processing, such as smoothing of raw data, an even higher success rate can be attained. Another approach would be to develop three separate neural network models and run them in parallel, and choose the best two out of three in case of a discrepancy. The resulting network will be rugged, and a trained network can be incorporated into a supervisory control and data acquisition (SCADA) system for a new generation fire detection system.

We have incorporated the above trained LVQ network into our LabView-based data acquisition system which connects with an On-Line 2010 Multi-Gas FT-IR spectrometer. A real time fire detection system has been constructed. Preliminary tests of this integrated software using the test data we described above has been satisfactory. However, these tests are in no way rigorous, as we have used the same experimental system to build the network. Additional tests (other burning materials, geometric arrangements, etc.) are needed in order to validate the accuracy and improve the robustness of the new fire detection system. The system also needs testing in a field installation.

To a large extent, the issue of how the system will respond to an unknown signal has been addressed by using a separate set of training fire tests and validation fire tests. Of course, one cannot test the entire universe of all possible gas concentration patterns that can be presented to the system. In general, it is well known that feed forward neural nets are typically very 
good at interpolation, but do rather poorly on extrapolation. Sometimes good extrapolation can be obtained if the actual physical phenomenon (which is not known) behaves like the data in the neural network training set.

The Learning Vector Quantization (LVQ) network used in this work is not a feed forward network, and it has a Kononen layer as its hidden layer. This network is more accurate than feed forward network and it can extrapolate if the network is well trained.

Some general comments regarding this technique: because of the inherent scaling nature of a neural network, it is not important where the gas concentrations are measured so long as the location of the measurement is not in the immediate vicinity of the flame. The same inherent characteristics of a neural network also may have the advantage of enabling this technique to be used for different facilities from those that the techniques have been tested for. We can also argue that a well-trained network using small scale fire test data can be applied to large and real scales. The current cost of an FT-IR spectrometer is about $\$ 40,000$ (US). The additional cost of a piping network would be comparable to existing commercialized AnaLASER and VESDA systems, and the operation and maintenance costs would be similar to these systems. The current system can be used more widely than these commercial systems (such as in particle-laden facilities) and with more development of the hardware, the cost can be significantly reduced.

\section{CONCLUSIONS}

It can be concluded that FT-IR spectroscopy can give multiple gas concentrations needed to build an advanced fire detection system. The gas concentration information together with intelligent data processing techniques can be used to identify fire or non-fire events as well as the modes of combustion, at least for the cases we have tested. Among the 248 sets of time series data for different fire and non-fire events, the Learning Vector Quantization network has correctly predicted $96 \%$ of the cases, a promising result for building a robust early fire detection system. Additional training and validation tests and software development will be needed to develop a field deployable fire detection system for high value facilities, such as semiconductor cleanrooms, telephone central offices, navy ships, aircraft and nuclear power plants.

\section{ACKNOWLEDGMENTS}

The support by the National Institute of Standards and Technology under Grant No. 50DKNB-5-00174, with Dr. William Grosshandler as Technical Monitor is greatly appreciated.

\section{REFERENCES}

1. Hall, J.R., "The Latest Statistics on U.S. Home Smoke Detection," Fire Journal, 83, 1, 39-41, 1989.

2. Blake, D. Airplane Class B Cargo Compartment Fire Protection, Annual Fire Research Conference, NISTIR 5280, 1993. 
3. Grosshandler, W.L., Editor, "Nuisance Alarms in Aircraft Cargo Areas and Critical Telecommunications Systems: Proceeding of the Third NIST Fire Detector Workshop," NISTIR 6146, March 1998.

4. Milke, J.A. and McAvoy, T.J, "Analysis of Signature Patterns for Discriminating Fire Detection with Multiple Sensors," Fire Technology, Second Quarter 1995.

5. Serio, M.A., Bonanno, A.S., Knight, K.S., Wójtowicz, M.A. and Solomon, P.R., "Advanced Infrared Systems for Detection of Building Fires," Final Report to DOC under Contract No. 50-DKNA-4-000-96, February 1995.

6. Okayama, Y., "Approach to Detection of Fires in Their Very Early Stage by Odor Sensors and Neural Net," Fire Safety Science-Proc. of 3rdt'l Symposium, pp. 955-964, 1991.

7. Okayama, Y., Ito, T. and Sasaki, T., "Design of Neural Net to Detect Early Stage of Fire and Evaluation by Using Real Sensors' Data," Fire Safety Science-Proc. of 4th Int'l Symposium, pp. 751-759, 1993.

8. Okayama, Y., "A primitive Study of a Fire Detection Method Controlled by Artificial Neural Net," Fire Safety Journal, pp. 535-553, 17, 1991.

9. Serio, M.A., Bonanno, A.S. Knight, K.S. and Newman, J.S., "Fourier Transform Infrared Diagnostics for Improved Fire Detection," Submitted for Publication in Fire Safety J., 1998.

10. Rumelhart, D.E., Hint, G.E. and Williams, R.J., "Learning Internal Representation by Error Propagation, Parallel Distributed Processing: Exploration in Micro Structure of Cognition," Vol. 1, Foundation, MIT Press, Boston, 1986.

11. McAvoy, T.J., Milke J. and Kunt, T.A. "Using Multivariate Statistical Methods to Detect fires," Fire Technology, First Quarter, 1994.

12. Milke, J.A., "An Application of Neural Networks for Discriminating Fire Detectors," AUBE 95, pp. 213-222, 1995.

13. Ishii, H., Ono, T., Yamauchi, Y. and Ohtani, S., "Fire Detection System by Multi-Layered Neural Network with Delay Circuit," Fire Safety Science-Proc. of 4th Int'1 Symposium, pp. 761-772, 1993.

14. Psichogios, D.C. and Ungar L.H., "A Hybrid Neural Network-First Principles Approach to Process Modeling," AIChe Journal, 38, No. 10, pp. 1499-1511, 1992.

15. Jackson, M.A. and Robins, I., "Gas Sensing of Fire Detection: Measurement of $\mathrm{CO}, \mathrm{CO}_{2}$, $\mathrm{H}_{2}, \mathrm{O}_{2}$, and Smoke density in European Standards Fire Tests," Fire Safety J., 22, pp. 181205, 1994.

16. Pfister, G., "Detection of Smoke Gases by Solid State Sensors-A Focus on Research Activities," Fire Safety J., 6, pp. 165-174, 1983.

17. Thuillard, M., "New Methods for Reducing the Number of False Alarms in Fire Detection Systems," Fire Technology, Second Quarter, pp. 250-268, 1994.

18. Kohonen, T., Neural Networks, 1, 3 (1988).

19. Jansson, P.A., Anal. Chem., 63, 357A (1991).

20. Kohonen, T., "Statistical Pattern Recognition with Neural Networks: Benchmark Studies," Proceedings of the Second Annual IEEE International Conference on Neural Networks, Vol. 1, 1988.

21. NeuralWare, Inc., NeuralWorks Professional II/Plus, Version 5.3, February 1997. 